\title{
LOS MERCADOS DE ABASTOS Y SU COMERCIALIZACIÓN COMO PRODUCTO DE TURISMO DE EXPERIENCIAS. EL CASO DE MADRID
}

\author{
Blanca García Henche
}

Universidad de Alcalá

\section{RESUMEN}

La demanda turística actual está viviendo una gran transformación. La experiencia se ha convertido en objeto esencial del viaje y el cliente siente cada vez más la necesidad de experimentar un destino para optimizar su vivencia del mismo. En este contexto, el turismo gastronómico adquiere gran relevancia y los mercados de abastos se posicionan como espacios turísticos.

El caso de la ciudad de Madrid sirve para ilustrar esta realidad, donde los mercados se convierten en recursos culturales, es decir, espacios que reivindican la gastronomía y el estilo de vida local como experiencia turística.

Palabras clave: mercados de abastos, turismo cultural, turismo gastronómico, turismo experiencial, Madrid.

\section{Experiential marketing food markets and its marketing as a product of tourism experiences. The case of Madrid}

\begin{abstract}
The current tourism is undergoing a great transformation. The experience has become essential travel object and customer feel more and more the need to experience a destination to optimize your experience of it. In this context, the culinary tourism acquires great relevance and the markets position themselves as tourist places.
\end{abstract}

Recibido: 11 de diciembre de 2015

Devuelto para su revisión: 10 de mayo de 2016

Aceptado: 4 de julio de 2016

Facultad de Ciencias Económicas y Turismo. Universidad de Alcalá. Plaza de la Victoria s/n. 28802 Alcalá de Henares. MADRID (España).E-mail: Blanca.garcia@uah.es 
The case of the city of Madrid serves to illustrate this reality, where markets become cultural resources, i.e. spaces which claim the gastronomy and the local lifestyle as tourist experience.

Keywords: food markets, cultural tourism, gastronomic tourism, experiential tourism, Madrid.

\section{INTRODUCCIÓN: TURISMO EXPERIENCIAL, UNA NUEVA TENDENCIA EN EL SECTOR TURÍSTICO}

A medida que el modelo tradicional de desarrollo turístico comienza a saturarse, las Administraciones Públicas y la propia industria turística deben buscar alternativas que proporcionen una respuesta a una demanda cada vez más exigente y segmentada y que busca autenticidad y experiencias en los destinos turísticos.

En la actualidad adquiere cada vez más importancia el turismo experiencial o emocional. Richards (2004) afirma que el turismo cultural está convirtiéndose en un producto de vivencia en el que la visita se juzga en función de todas las características del lugar y no solo por su valor cultural.

Así el patrimonio cultural intangible se convierte en un recurso clave de diferenciación de los destinos turísticos y España, en este sentido, además de patrimonio material (museos, iglesias, edificios emblemáticos...), posee una gran y diversa oferta gastronómica para poner en valor, mostrando el estilo de vida local.

Desde finales de los años noventa se percibe una mayor atención acerca de la calidad y la experiencia turística, así como la valoración del patrimonio y el paisaje en sentido integral. Las experiencias turísticas parecen identificarse cada vez más como el verdadero producto (Cuenca y Prat, 2012). Por todo ello, en la actualidad, adquiere cada vez más importancia el turismo experiencial o emocional.

Estas tendencias son las que han propiciado la aparición y el alto grado de crecimiento de la oferta de turismo urbano de experiencias a las que dan respuesta los barrios "destino turístico", como es el caso del Barrio de Las Letras o Triball en Madrid, los mercados de abastos, los cursos de cocina local, etc.

El turismo experiencial es la tendencia del presente en el sector turístico, donde la experiencia es objeto esencial del viaje y el cliente siente cada vez más la necesidad de experimentar un destino para optimizar su vivencia del mismo. Al integrar aspectos como la cultura y las tradiciones de las gentes del lugar, el turista se siente inmerso en su forma de vida local y obtiene una imagen positiva del destino visitado.

Algunas de las dimensiones de la autenticidad percibida por los turistas (Wang, 1999) son la autenticidad objetiva, referida a la singularidad de los recursos patrimoniales y territoriales que sirven de soporte a los productos turísticos y la autenticidad constructiva, que hace referencia a la construcción social sobre lo que se considera que tiene valor y atractivo turístico. En este sentido, los mercados de abastos constituyen un recurso turístico que los nuevos perfiles de consumidores valoran como recursos que aportan autenticidad objetiva y constructiva a los destinos. 
Según las últimas tendencias de la demanda, los denominados "turistas de última o tercera generación" aprovechan su estancia en los destinos urbanos para buscar experiencias enriquecedoras y vivencias únicas. Así, se pasa de un turista pasivo, mero espectador, a un turista activo, que en lugar de "observar" se desplaza al destino para "hacer" algo, involucrándose más en la cultura local.

Ya no es suficiente ofrecer tranquilidad, un entorno natural, una gran cantidad de recursos turísticos o la belleza del lugar. A todo eso, ahora, hay que añadirle experiencias, es decir, un contacto más intenso y auténtico con los habitantes, innovación, autenticidad, sorpresa, historias y vivencias y emociones.

No es lo mismo visitar un destino que sentir un destino (olores, colores, gusto, texturas...) y vivir un destino con sus habitantes. Hay que integrarse en la forma de vivir y en la cultura propia de cada lugar, impregnándose de todo lo intangible hacia la creación de un recuerdo que perviva después del viaje y que pueda ser transmitido a los demás.

Esta nueva tendencia, busca establecer una relación emocional entre el turista y el destino. La "economía de la experiencia" (Pine y Gilmore, 1998) lleva a las ciudades a convertirse en escenarios en los que se crean experiencias. En esta economía de la experiencia, la cultura se convierte en una materia prima esencial y el turismo cultural es un elemento cada vez más importante, más aún en España donde la gastronomía es parte primordial del patrimonio cultural.

Los actuales viajeros, consideran las experiencias culinarias como un elemento clave a la hora de elegir el destino. Esa búsqueda de lo local lleva a los turistas a visitar los mercados de abastos, donde se puede percibir la idiosincrasia de la gente local, su forma de expresarse, de vender, de comprar, sus hábitos alimenticios, el estilo de vida de disfrute del ocio, los gustos y costumbres gastronómicas, etc.

En un mundo estandarizado y globalizado, el turista amante de nuevas experiencias busca algo insólito, diferente y exclusivo, que únicamente se encuentre en aquel destino concreto que se visita de forma expresa. Los monumentos, los museos, la idiosincrasia de la gente, los mercados de abastos son exponentes de lo que esos nuevos consumidores buscan, puesto que ofrecen experiencias auténticas, propias de la sociedad local que se visita. En este sentido, los mercados de abastos son uno de los recursos turísticos promocionados donde lo local y lo turístico se dan la mano.

No se ha de olvidar que, en turismo, no se venden realmente productos, sino que se venden experiencias (Vogeler y Hernández, 2002). El turista que busca experiencias es aquel que quiere evadirse, descubrir, disfrutar y conectar con la gente del lugar y con sus costumbres; por ello, los mercados pueden, y deben, ser parte de esa experiencia buscada por los turistas. En ese sentido, España tiene una gran oferta de productos a ofrecer en muy diferentes destinos.

\section{LOS MERCADOS DE ABASTOS COMO RECURSO TURÍSTICO}

El patrimonio cultural es el conjunto de bienes, materiales e inmateriales, que son identificados por una sociedad concreta como portadores de valores culturales propios de la comunidad. Son bienes tangibles e intangibles que tienen un alto contenido simbólico, lo que les hace merecedores de una especial protección no sólo relacionada con su conservación sino también con el uso que se pueda hacer de ellos (Harrison, 1994;Ballart y Juan-Tresseras, 2001, Hernández, 2002). 
Este patrimonio cultural se representa tanto en materiales tangibles (museos, catedrales, palacios...) fácilmente enumerados, como en materiales intangibles (tradiciones, gastronomía, estilos de vida, paisajes...) difíciles de enumerar, pero que dan un gran apoyo a la simbología de cualquier ciudad y consolidan su imagen turística (Troitiño, 1996). Por tanto, cuando se habla de patrimonio cultural se ha de incorporar además del patrimonio histórico, otras manifestaciones como la lengua, la artesanía, la gastronomía, etc.

Según el informe Food Tourism 2014, que recoge la opinión de 389 profesionales del sector turístico en cinco países, España lidera el ránking a nivel europeo en el que la oferta gastronómica es un factor clave a la hora de elegir un destino turístico.

España fue valorada por un $82 \%$ de los profesionales como destino atractivo por su oferta gastronómica, por delante de Reino Unido (73\%), Italia (61\%), Francia (60\%) y Alemania (55\%). Este análisis, realizado por The Blueroom Project-TBP Consulting en colaboración con Pangaea Network, cuenta con la colaboración de profesionales, de los cuales un $69 \%$ son agentes de viajes y touroperadores.

La gastronomía en España es un valor diferencial que aporta competitividad frente a otros destinos. Es, por tanto, un factor destacable de nuestro sector turístico y supone, además, una gran fortaleza de nuestro país como destino turístico de experiencias.

La cocina española es actualmente la segunda comida preferida de los europeos, situándose sólo por detrás de la italiana, según la encuesta anual sobre Viajes y Gastronomía realizada por la Web de viajes TripAdvisor entre usuarios del continente.

Según la última encuesta Habitur, elaborada por el Instituto de Estudios Turísticos (IET), que mide anualmente los hábitos de los visitantes extranjeros, la gastronomía figura como valor destacado entre la satisfacción de los turistas internacionales que visitan el país y, especialmente, algunos destinos.

Por todo ello, el mundo de la gastronomía nacional se pone en valor destacando la necesidad de impulsar este nuevo producto turístico apostando, sobre todo, por una mejor promoción, comercialización y diseño de productos basados en experiencias gastronómicas.

En el escenario turístico actual, el turismo gastronómico adquiere cada vez más relevancia en España. La gastronomía como recurso turístico de nuestro país es un recurso esencial de nuestro patrimonio que está dado una imagen de innovación, calidad, excelencia y autenticidad, que se está aprovechando desde Turespaña como estrategia para diversificar nuestra oferta turística (Véase Figura 1). Por ello, los mercados de abastos se están convirtiendo en un servicio/recurso clave de la oferta de turismo cultural, cuya base es la venta de una experiencia gastronómica única, posicionándose como patrimonio intangible de la cultura de un territorio.

Según el informe Food Tourism 2014, las actividades que principalmente realizan los turistas interesados en el turismo gastronómico son esencialmente la visita a granjas y mercados, los eventos relacionados con el vino y la compra de productos locales, tal como recoge la Figura 2.

En el caso de Madrid, como en otras grandes ciudades, los mercados de abastos son excepcionales espacios llenos de historia y cultura de un territorio, edificios emblemáticos, con localizaciones que son, en sí, un recurso patrimonial, arquitectónico o histórico. 
Figura 1

ESTRATEGIAS DE PROMOCIÓN DE LOS MERCADOS DE ABASTOS EN DEL PORTAL DE TURESPAÑA

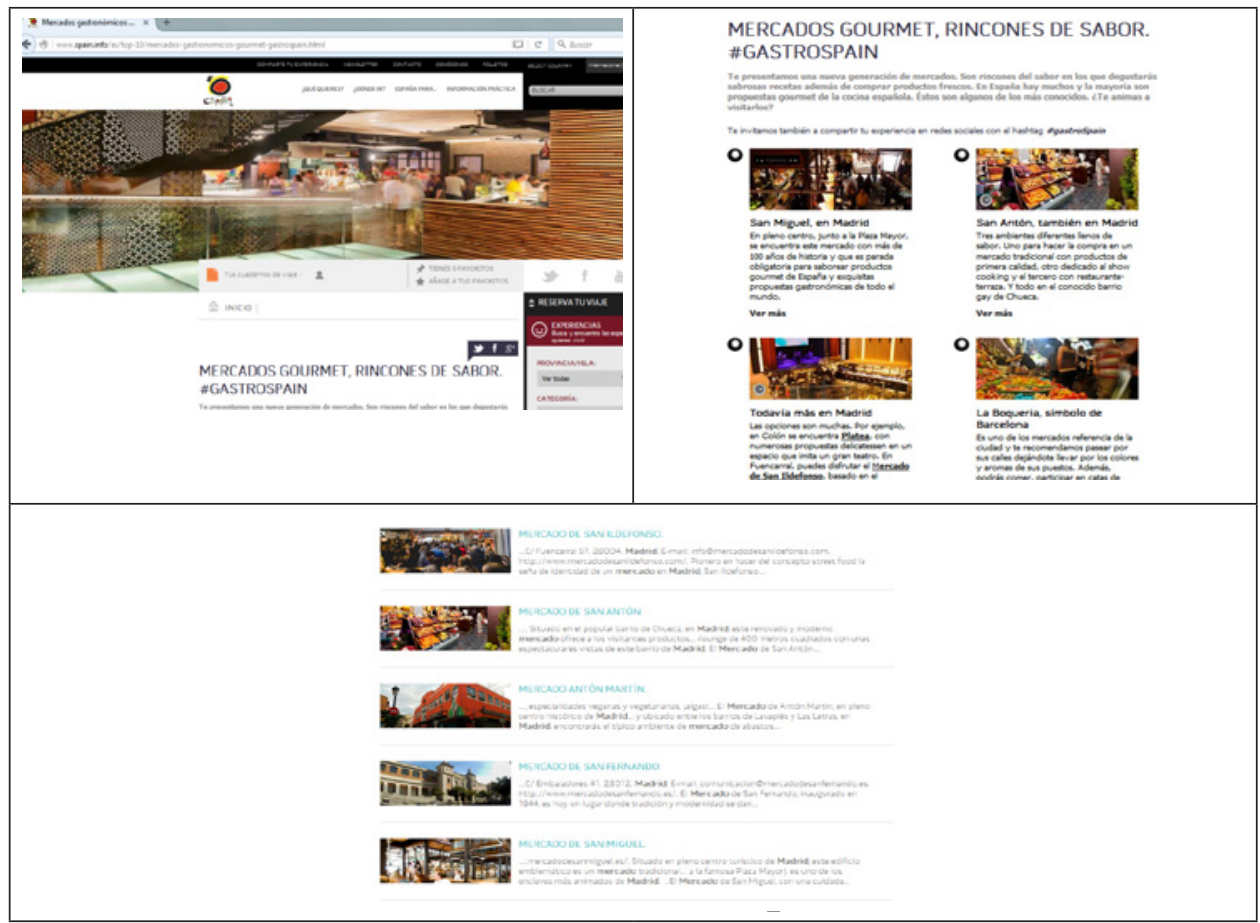

Fuente: www.spain.info

Figura 2

\section{ACTIVIDADES REALIZADAS POR LOS VIAJEROS QUE BUSCAN EXPERIENCIAS GASTRONÓMICAS}

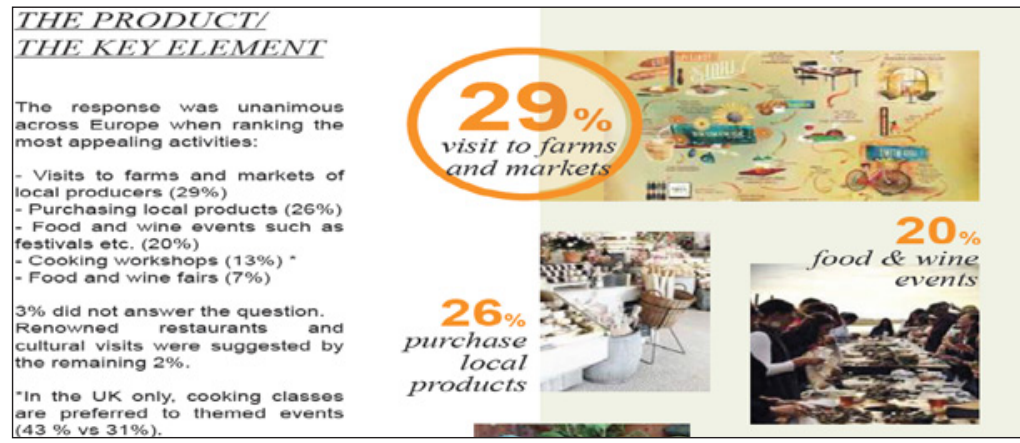

Fuente: http://www.blueroom.es/noticia/ya-esta-disponible-food-tourism-2014-nuevo-estudio-de-blueroom-project/ 
La llegada de los turistas a dichos mercados permite incrementar ingresos y remodelar y diversificar los puestos, permite la remodelación del conjunto arquitectónico (bastante deteriorado y obsoleto en algunas ocasiones), proponer una oferta más orientada a los visitantes forasteros, abrir por las tardes o los sábados e incluso domingos e introducirlos como lugares de paso en las rutas de la zona (Crespí et. al, 2013). Permite, en definitiva, construir una nueva oferta turística de lugares de experiencias (Barrado, 2004) en los que poder experimentar una "cotidianeidad extraordinaria" (Quaglieri y Russo, 2010).

Ese cambio de oferta de los mercados, en el caso de España, viene dado, principalmente, por el aumento de la oferta de hostelería en los mercados de abastos, habilitando zonas de ocio para comer, con una oferta novedosa de bares de tapas, pequeños restaurantes ubicados junto a los puestos de verduras, fruta o pescado, tiendas que son también oferta de hostelería etc.

Este fenómeno de los mercados como recurso turístico no es un caso únicamente español, ya son muchos los mercados en otros países que constituyen recursos turísticos de primer orden: el Markthalle de Stuttgart, el Mercado de San Lorenzo de Florencia, el Mercado Central de Budapest, Borough Market en Londres, los numerosos mercados al aire de libre de Paris o el mercado flotante de Bangkok, son ejemplos destacables.

La importancia de la gastronomía como motor de arrastre para el turismo quedó patente en la celebración de la Cumbre Internacional de Gastronomía Madrid Fusión (2015) en la que se comprobó que la determinación de apoyar y promocionar la oferta gastronómica de una ciudad puede servir de dinamizador económico y foco de atracción turística.

Madrid Fusión se ha consolidado como el gran escenario mundial de la gastronomía y durante su celebración Madrid se convierte en la capital mundial de la gastronomía.

Como se aprecia en la Tabla 1, Madrid Fusión muestra que la gastronomía es una marca fundamental para la capital e indudable motor de arrastre para el turismo.

\section{Tabla 1 \\ INDICADORES DE LA EDICIÓN MADRID FUSIÓN 2015}

\begin{tabular}{|l|l|}
\hline Indicadores relevantes de Madrid Fusión 2015 & \\
\hline Numero de congresistas & 1100 (30\% internacionales) \\
\hline Inscripciones & 3200 \\
\hline Ponentes & 103 (30 internacionales) \\
\hline Personas acreditadas durante los tres días & 10.126 \\
\hline Expositores & 150 (22 internacionales) \\
\hline Periodistas acreditados & 650 (40\% prensa internacional) \\
\hline $\begin{array}{l}\text { Visitas al sitio web www.madridfusion.net } \\
\text { (del 16 de enero al 16 de febrero de 2015) }\end{array}$ & 110.000 \\
\hline Consultas a la APP Madridfusión & 2500 \\
\hline Apariciones en prensa escrita (medios nacionales e internacionales) & 802 \\
\hline Tiempo de aparición en televisión & 1 hora 45 minutos 40 segundos \\
\hline
\end{tabular}

Fuente: www.madridfusion.net/contenidos/pdf/widgets/24ES.pdf 


\section{MERCADOS DE MADRID Y SU OFERTA DE TURISMO EXPERIENCIAL}

Algunos de los mercados de abastos de Madrid se han convertido en uno de los atractivos turísticos o "sights" indispensables del centro histórico de la ciudad. Así, Madrid, se convierte en un referente en lo relativo al turismo de mercados, ya que los mercados de abastos se han transformado en una forma de acercamiento a la cultura local de la ciudad.

En esta realidad, se ha considerado conveniente analizar el rol de los mercados de abastos como recurso de valor cultural en el turismo urbano, analizando el caso de Madrid. En concreto se analizan los mercados de San Miguel, San Antón, Antón Martín, San Fernando, Barceló, La Cebada, Vallehermoso, Mercado de la Paz, Huerto del Lucas, Platea y San Ildefondo, ya que son los que realizan más actividades relacionadas con experiencias turísticas y los que han diseñado un espacio no sólo de compra, sino también de ocio y de aprendizaje sobre la gastronomía.

Es evidente que la gastronomía muestra la identidad de un destino turístico, por ello, los mercados de abastos pueden ser, en sí mismos, un atractivo turístico. Así, en Madrid, la oferta de dichos mercados se convierte en un atractivo turístico de la ciudad, bien sea por los productos que vende, por el ambiente, por su oferta de ocio, por su arquitectura, etc.

Según Comunicatur (2011) se podría realizar una rápida clasificación de mercados "turísticos" por tipologías:

- Mercados tradicionales renovados, como el mercado de Antón Martín, Vallehermoso, La Cebada, Barceló, La Paz o San Fernando, en Madrid.

- Mercados "reinventados", como el Mercado de San Miguel o San Antón de Madrid.

- Mercados al aire libre, como el Rastro de Madrid Mercados de día o el Mercado de Productores de la Cámara Agraria en Matadero de Madrid.

- Mercados "pervertidos" que han mantenido la estructura del edificio pero donde dentro sólo encontramos tiendas de moda internacional y restaurantes de comida rápida.

La mayor parte de los mercados que están ofreciéndose como recurso turístico en Madrid son los que Comunicatur (2011) denomina "mercados tradicionales renovados" y "mercados reinventados". En ambos casos, el atractivo principal es la combinación de lo tradicional y lo moderno.

La Tabla 2 recoge la oferta de mercados de abastos que están realizando actividades de marketing experiencial, según la categorización de mercados tradiciones y mercados reinventados. Además, se ha considerado añadir nuevos espacios gastronómicos, que operan como mercados en lugares donde tradicionalmente no existía un mercado de abastos y que se centran sus servicios en hostelería y restauración dedicada al turismo gastronómico. 
Tabla 2

\section{CLASIFICACIÓN DE MERCADOS DE MADRID RECURSO TURÍSTICO}

\begin{tabular}{|l|l|l|l|}
\hline \multicolumn{1}{|c|}{ Mercado } & Barrio Turístico & Reapertura & \multicolumn{1}{c|}{ Tipo de clasificación } \\
\hline San Miguel & Austrias & 2009 & Mercados reinventados \\
\hline San Antón & Chueca & 2011 & Mercados reinventados \\
\hline Antón Martín & Las Letras/Lavapiés & 2012 & Mercados tradicionales renovados \\
\hline San Fernando & Lavapiés & 2010 & Mercados tradicionales renovados \\
\hline Barceló & Salesas & 2014 & Mercados tradicionales renovados \\
\hline La Cebada & La Latina & 2009 & Mercados tradicionales renovados \\
\hline Vallehermoso & $\begin{array}{l}\text { Argüelles } \\
\text { Conde Duque }\end{array}$ & 2014 & Mercados tradicionales renovados \\
\hline Mercado de La Paz & Salamanca & 2014 & Mercados tradicionales renovados \\
\hline Huerto de Lucas & Salesas & 2014 & Nuevos espacios gastronómicos \\
\hline Platea & Salamanca & 2014 & Nuevos espacios gastronómicos \\
\hline San Ildefonso & Chueca/Malasaña & 2014 & Nuevos espacios gastronómicos \\
\hline
\end{tabular}

Fuente: elaboración propia.

Otros estudios establecen diferentes clasificaciones para los mercados de abastos, como la identificación de los mismos según su orientación al mercado (Crespí,et al. 2013):

- Mercados turistificados, como San Antón, San Miguel o Platea, que están claramente orientados al turista y al público local de clases medias y altas (gentries) con un fuerte impacto sobre el área funcional.

- Mercados sostenibles, como el San Fernando, Antón Martín, La Cebada, Vallehermoso o La Paz, que son mercados que combinan los antiguos usos comunitarios, renovándose y compaginándolos con el reclamo turístico, lo cual permite una convivencia más acorde con la actual ciudad y sus residentes.

En Madrid, los mercados analizados, han sabido potenciar su espacio llegando a generar importantes flujos económicos y sociales en sus barrios. En 2003, el Ayuntamiento de Madrid inició un Plan de Innovación y Transformación de sus mercados, mejorando la seguridad, suprimiendo barreras arquitectónicas, reformando fachadas e instalaciones, etc. Esta reinvención ha llevado a los mercados a posicionarse como "destinos experienciales" dentro de la propia ciudad, respondiendo la fórmula general en la mayoría los mercados al modelo: mercado tradicional+oferta gourmet+actividades culturales y de ocio (Figura 3).

La oferta de mercados de abastos de Madrid, que operan como oferta turística y de ocio, es, por tanto, muy variada. Todos ellos centran su oferta en tres conceptos: la temporalidad (productos de temporada), la flexibilidad horaria y la degustación (probar el producto antes de llevarlo a casa). 
Figura 3

INFORMACIÓN SOBRE ACTIVIDADES CULTURALES Y DE OCIO EN LOS MERCADOS DE MADRID

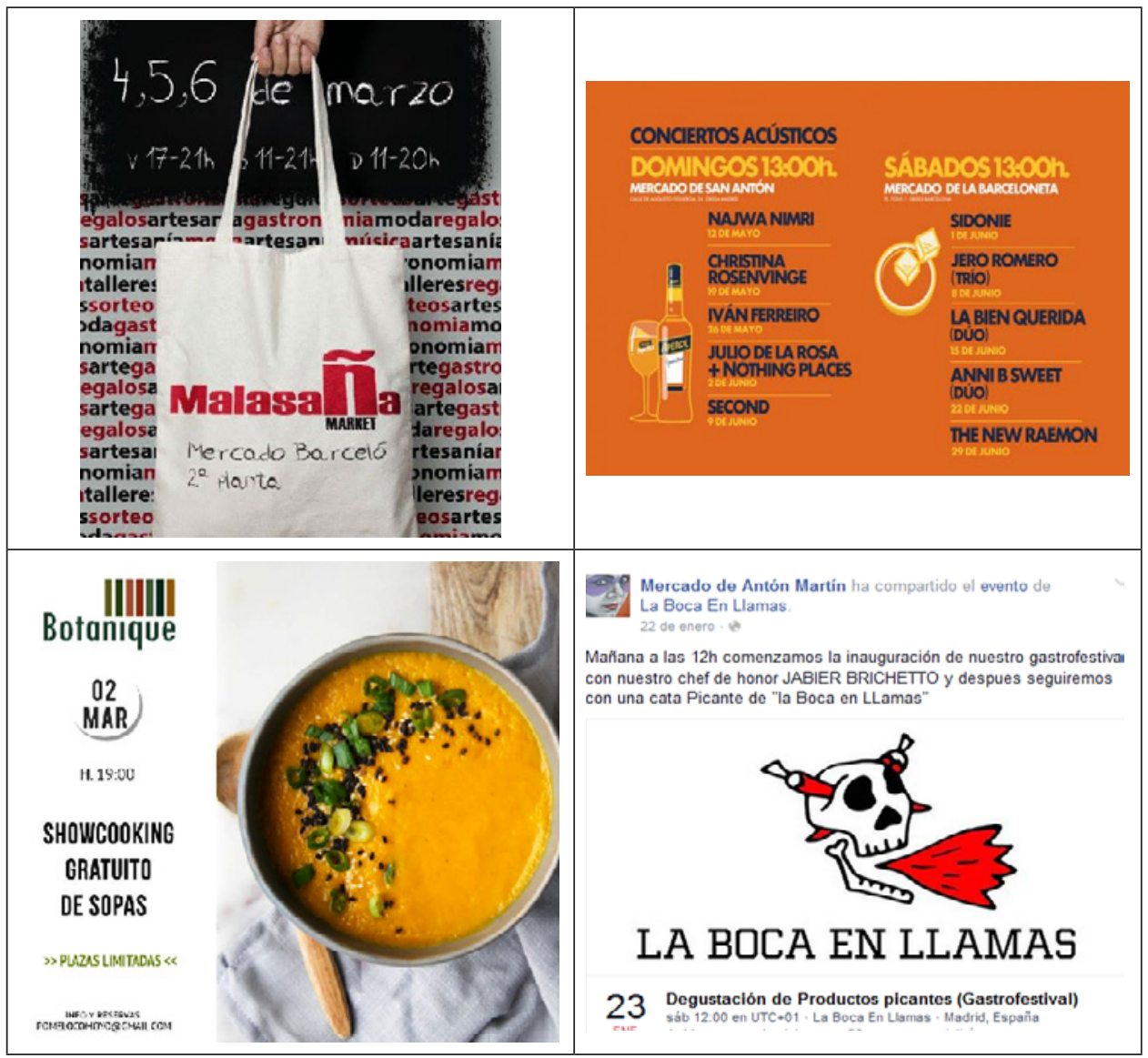

Fuente: www.mercadobarcelo.es/; www.mercadosananton.com; www.mercadoantonmartin.com

Existen algunos ítems que muestran como los mercados buscan una mayor adaptación a los nuevos usos turísticos y de ocio:

- Los horarios de dichos mercados se amplían para los usos de ocio y restauración.

- Aumenta el empleo de puestos para establecimientos de ocio y restauración (restaurantes, tiendas gourmet que poseen servicio de bar, bares o zonas de ocio común para la restauración).

- Los mercados se posicionan como atractivos turísticos en el mapa turístico de Madrid.

- Los mercados se promocionan en la web de promoción de la ciudad www.esmadrid.com 
- Los mercados se posicionan en lugares visibles en los buscadores de Internet como Tripadvisor, ya que para los nuevos viajeros Internet supone la posibilidad de desempeñar un papel más activo en los procesos de comunicación, facilitando la obtención y el intercambio de información y opiniones (García, 2011).

La Figura 4 y la Tabla 3 recogen algunas de las acciones comerciales de los mercados de Madrid, mencionadas con anterioridad.

Todos los mercados han sabido sacar provecho a lo bellos de sus renovadas instalaciones para sobrepasar la vía de venta de gastronomía y entrar en la dimensión de la cultura social, convirtiéndose en lugares donde vivir una experiencia gastronómica completa.

\section{Figura 4 \\ INFORMACIÓN RECOGIDA EN LA WEB DE TURISMO \\ SOBRE EL TURISMO DE COMPRAS Y, EN CONCRETO, SOBRE LOS MERCADOS DE ABASTOS}

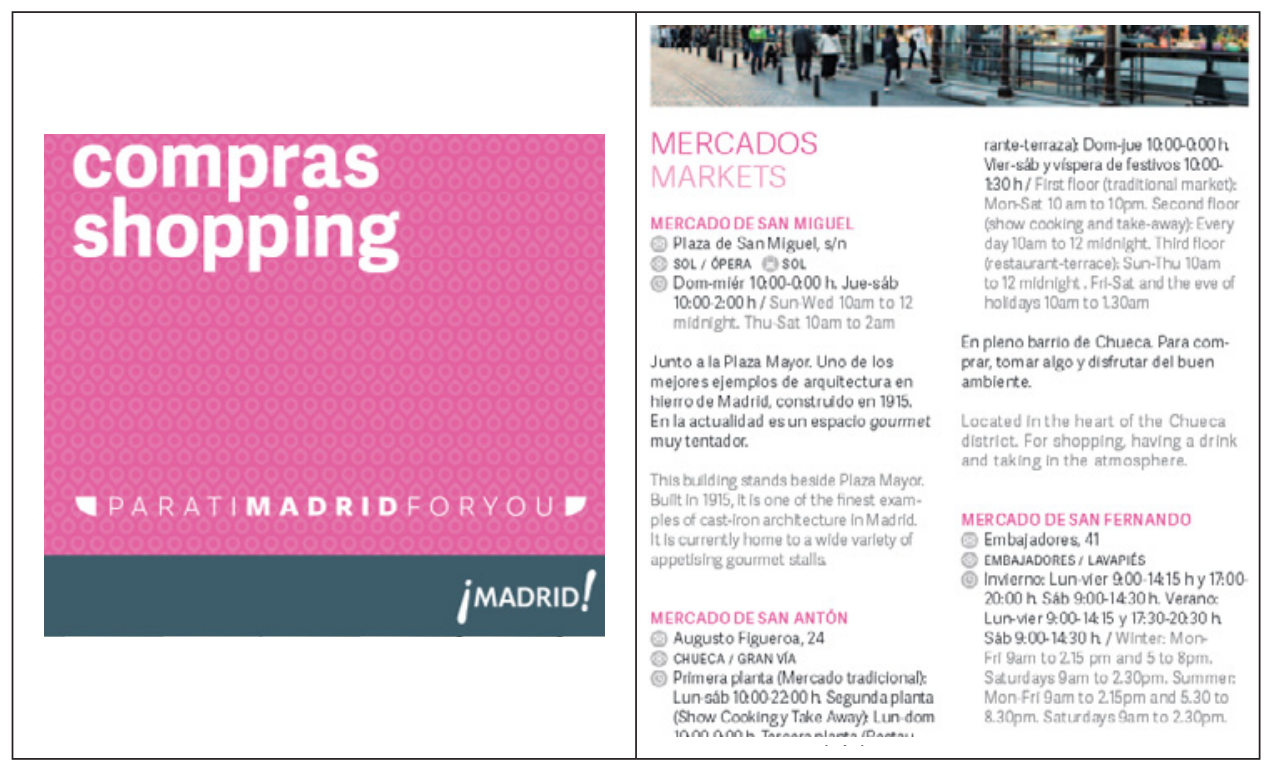

Fuente: www.esmadrid.com

Como se mencionó con anterioridad, una de las actividades más importantes a nivel gastronómico en Madrid es Madrid Fusión. Entre las actividades paralelas a Madrid Fusión se realiza un evento clave a nivel de marketing de experiencias en la ciudad: Gastrofestival.

En la edición de 2016 los mercados de abastos se han convertido en parte esencial de la comercialización de actividades gastronómicas, como recoge la Tabla 4. Los mercados de abastos se convierten, así en un recurso turístico ofreciendo servicios turísticos basados en la gastronomía como experiencia. 
Tabla 3

\section{ACCIONES DE COMERCIALES DE LOS MERCADOS EXPERIENCIALES DE MADRID}

\begin{tabular}{|c|c|c|c|c|}
\hline Mercado & Horario & $\begin{array}{l}\text { Establecimientos } \\
\text { de ocio } \\
\text { Hostelería }\end{array}$ & $\begin{array}{l}\text { Aparición } \\
\text { mapa } \\
\text { turístico } \\
\text { Madrid }\end{array}$ & $\begin{array}{l}\text { Tripadvisor } \\
\text { Aparece o no } \\
\text { Valoración }\end{array}$ \\
\hline San Miguel & $\begin{array}{l}\text { L-M-X-D 10:00 a 24:00 } \\
\text { J-V-S 10:00 a 2:00 }\end{array}$ & & & $\begin{array}{c}\text { Certificado de excelencia. } \\
\mathrm{N}^{\circ} 10 \text { de } 643 \text { cosas que } \\
\text { hacer en Madrid. } \\
4,5 / 5 \text { estrellas }\end{array}$ \\
\hline San Antón & $\begin{array}{l}\text { Primera Planta 10-22 Segunda Planta 10-24 Tercera } \\
\text { Planta D-J 10-24 V-S y Festivos 10-1:30 }\end{array}$ & & & $\begin{array}{l}\text { No } 45 \text { de } 643 \text { cosas que } \\
\text { hacer en Madrid. } \\
\text { 4/5 estrellas }\end{array}$ \\
\hline Antón Martín & $\begin{array}{l}\text { Establecimientos del Mercado Tradicional. } \\
\text { De Lun-Vie de } 9 \text { a } 21 \text { y Sáb de } 9 \text { a } 15 \mathrm{~h} \\
\text { Horario de Restauración. } \\
\text { De Lun-Sáb de } 9 \text { a } \mathbf{2 3 : 3 0 h .}\end{array}$ & & & $\begin{array}{l}\text { Certificado de excelencia. } \\
4,5 / \text { estrellas. } \\
\mathrm{N}^{\circ} 84 \text { de } 643 \text { cosas que } \\
\text { hacer en Madrid }\end{array}$ \\
\hline San Fernando & $\begin{array}{l}\text { L 9:00 a 14:00 17:00 a21:00 } \\
\text { M-X-J 9:00 a 21:00 } \\
\text { V-S 9:00 a 23:00 } \\
\text { D 11:00 a 17:00 }\end{array}$ & & & $\begin{array}{l}\mathrm{N}^{\circ} 151 \text { de } 643 \text { cosas que } \\
\text { hacer en Madrid. } \\
4,5 / 5 \text { estrellas }\end{array}$ \\
\hline Barceló & $\begin{array}{l}\text { Planta } 0 \text { y } 1 \\
\text { L-M-X-J-V 9:00 a 14:00 - 17:30 a 20:30 } \\
\text { S 9:00 a 15:00 } \\
\text { Planta 2 } \\
\text { L-M-X-J-V 9:00 a 15:00 }\end{array}$ & & & NO \\
\hline La Cebada & $\begin{array}{l}\text { De lunes a viernes de } 9 \text { a } 14 \text { y de } 17: 30 \text { a } 20: 30 \text { horas. } \\
\text { Sábado de } 9 \text { a } 15 \text { horas. }\end{array}$ & & & $\begin{array}{c}\mathrm{N}^{\circ} 14 \text { de } 177 \text { compras en } \\
\text { Madrid. } \\
4,5 / 5 \text { estrellas }\end{array}$ \\
\hline Vallehermoso & $\begin{array}{l}\text { De Lun-Sab de } 9 \text { a 14h; } 17: 00 \text { a 20:30 } \\
\text { y Sáb de } 9 \text { a } 15 \mathrm{~h} \\
\text { Horario de Restauración. } \\
\text { De Lun-Sáb } 10 \text { a } \mathbf{2 3 : 3 0 h} \\
\text { Domingo de } \mathbf{1 1} \text { a } \mathbf{1 7 . 0 0}\end{array}$ & & & NO \\
\hline $\mathrm{La} \mathrm{Paz}$ & $\begin{array}{l}\text { De Lun-Sab de } 9 \text { a 14.30h; } 17: 00 \text { a 20:30 } \\
\text { y Sáb de } 9 \text { a } 15 \text { h }\end{array}$ & & & $\begin{array}{l}\mathrm{N}^{\circ} 139 \text { de } 643 \text { cosas que } \\
\text { hacer en Madrid. } \\
4,5 / 5 \text { estrellas }\end{array}$ \\
\hline $\begin{array}{l}\text { Huerto de } \\
\text { Lucas }\end{array}$ & $\begin{array}{l}\text { L-M 10:00 a 20:00 } \\
\text { X-J-V-S 10:00 a 22:00 } \\
\text { D 11:00 a 17:00 } \\
\text { Horario Cantina X-J-V-S 10:00 a 00:00 D 11:00 a 17:00 } \\
\text { Horario carnicería M-X-J-V-S 10:00 a 20:00 } \\
\text { Horario arbórea M-X-J-V-S 10:00 a 23:00 }\end{array}$ & & & $\begin{array}{l}\mathrm{N}^{\circ} 1369 \text { de } 8276 \\
\text { restaurantes en Madrid. } \\
\text { 4/5 estrellas }\end{array}$ \\
\hline Platea & $\begin{array}{l}\text { D-L-M-X 12:00 a 00:30 } \\
\text { J-V-S 12:00 a 2:30 } \\
\text { Horario Gold Gourmet L-M-X-J-S 9:00 a 21:00 } \\
\text { D 10:00 a 21:00 } \\
\text { Horario Mamá Framboise L-M-X-J-V-S 9:00 a 21:00 } \\
\text { D 10:00 a 21:00 }\end{array}$ & & & $\begin{array}{l}\mathrm{N}^{\circ} 247 \text { de } 8276 \\
\text { restaurantes en Madrid. } \\
4 / 5 \text { estrellas }\end{array}$ \\
\hline San Ildefonso & $\begin{array}{l}\text { L-M-X 12:00 a 0:00 } \\
\text { J-V-S 12:00 a 1:00 } \\
\text { D 12:00 a 0:00 }\end{array}$ & $V$ & $v$ & $\begin{array}{l}\mathrm{N}^{\circ} 172 \text { de } 8276 \\
\text { restaurantes en Madrid. } \\
4 / 5 \text { estrellas }\end{array}$ \\
\hline
\end{tabular}

Fuente: elaboración propia y webs de los mercados; www.esmadrid.com; www.tripadvisor.com (Diciembre, 2015) 
En la promoción del Gastrofestival, se han ofertado actividades exclusivas de los mercados de abastos, como se observa en la web informativa del mismo y en los carteles y folletos promocionales situados en los diferentes mercados de abastos (Figuras 5, 6 y 7).

Como conclusión se podría decir que la nueva tendencia de los mercados como destinos experienciales viene pisando fuerte gracias a las actividades de ocio y restauración ofertadas por los mismos. Se asiste así, a una reinvención del mercado de abastos tradicional.

Los puestos vacíos han sido recuperados por cocineros y emprendedores transformando los mercados en lugares donde vivir "vivir una experiencia gastronómica" y, por tanto, una oferta adaptada a las nuevas exigencias de los consumidores turísticos en busca de lo "local".

Figura 5

WEB PROMOCIONAL GASTROFESTIVAL 2016 CON ACTIVIDADES EN LOS MERCADOS

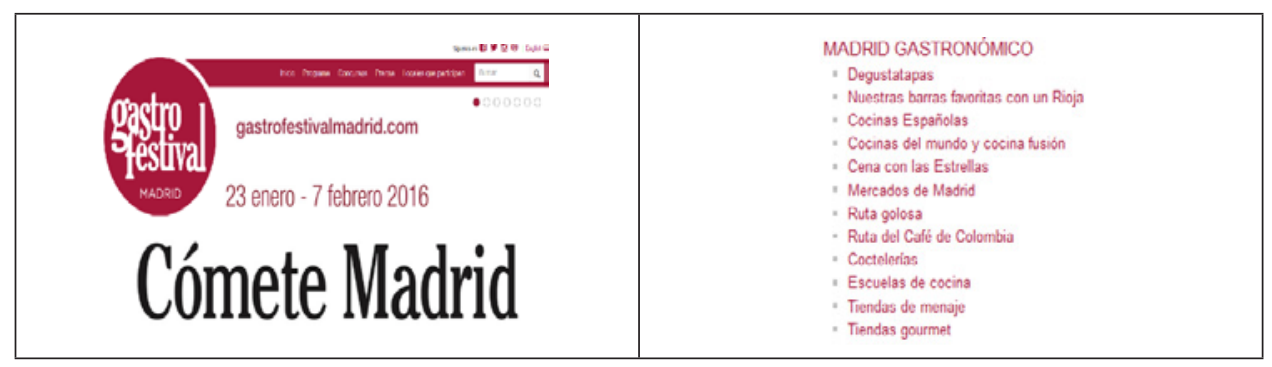

Fuente: www.gastrofestivalmadrid.com

Figura 6

CARTEL PROMOCIONAL DE GASTROFESTIVAL 2016 EN EL MERCADO DE ANTÓN MARTÍN

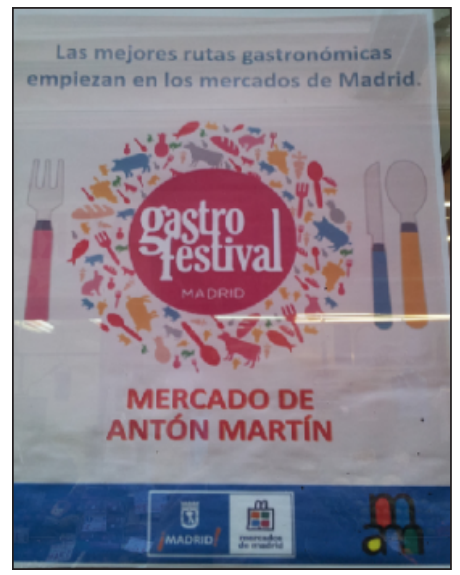

Fuente: elaboración propia 
Tabla 4

ACTIVIDADES DE LOS MERCADOS

DE ABASTOS EN EL GASTROFESTIVAL 2016

\begin{tabular}{|c|c|c|}
\hline Mercado & Barrio & Actividad en Gastrofestival \\
\hline San Antón & Chueca & Carrito Gourmet del Gastrofestival \\
\hline Antón Martín & $\begin{array}{l}\text { Barrio de las Letras/ } \\
\text { Lavapiés }\end{array}$ & $\begin{array}{l}\text { Inauguración del Gastrofestival } \\
\text { Talleres variados de cocina fusión } \\
\text { Tapas de mercado } \\
\text { Menús Gastrofestival } \\
\text { Talleres para los cinco sentidos } \\
\text { Productos Gastrofestival } \\
\text { Taller: los niños se divierten cocinando verduras y } \\
\text { frutas }\end{array}$ \\
\hline Barceló & Salesas & $\begin{array}{l}\text { Cata a ciegas } \\
\text { Escuela de cocina para niños }\end{array}$ \\
\hline Vallermoso & $\begin{array}{l}\text { Argüelles/Conde } \\
\text { Duque }\end{array}$ & $\begin{array}{l}\text { Demostración de elaboración de sushi } \\
\text { Gran cocido madrileño } \\
\text { Degustación de Tés } \\
\text { Degustación de aperitivos italianos } \\
\text { Fiesta del marisco } \\
\text { Taller de fabricación de cerveza } \\
\text { Al vino, pan y viceversa } \\
\text { Degustación de sobaos y quesadas } \\
\text { Brunch asiático } \\
\text { Historia, elaboración y degustación de queso } \\
\text { artesanal de Calaveruela }\end{array}$ \\
\hline Mercado de La Paz & Salamanca & $\begin{array}{l}\text { Degustación de productos franceses } \\
\text { Degustación de productos italianos } \\
\text { Productos de la tierra-productos del mar }\end{array}$ \\
\hline
\end{tabular}

Fuente: www.gastrofestivalmadrid.com/es/cabecera/10/mercados-de-madrid

\section{MERCADOS DE MADRID: NUEVAS FORMAS DE COMUNICACIÓN CON LOS CLIENTES EXPERIENCIALES}

Con los mercados de abastos se asiste a las primeras fases de desarrollo del ciclo de vida de un nuevo producto/recurso turístico, que conlleva, también, nuevas estrategias de comunicación con el nuevo segmento de mercado al que van dirigidos.

Por todo ello, respecto a las estrategias de comunicación con el mercado objetivo, se ha de observar que los nuevos turistas que viajan por su cuenta son más independientes y usan Internet y otros medios de comunicación on line para informarse de las actividades en el destino. Ante este panorama, los mercados de abastos han considerado el uso de las redes sociales y el ciber espacio como su principal herramienta de comunicación con 
el nuevo nicho de mercado turístico que busca nuevas experiencias, utilizando webs, redes sociales como Facebook y Twitter y blogs, como instrumentos de promoción.

El enorme impacto que la Web 2.0 y 3.0 tiene en la actividad turística alcanza a proveedores, oferentes y consumidores. El "boca oreja”, tan importante en el marketing turístico, se ve ahora potenciado por los miles de contactos que un usuario activo en internet puede generar mediante blogs, correo electrónico, su cuenta de Facebook, Twitter, Instagram, etc.

Figura 7

FOLLETO INFORMATIVO DEL GASTROFESTIVAL 2016, SECCIÓN DEDICADA A LOS MERCADOS DE ABASTOS

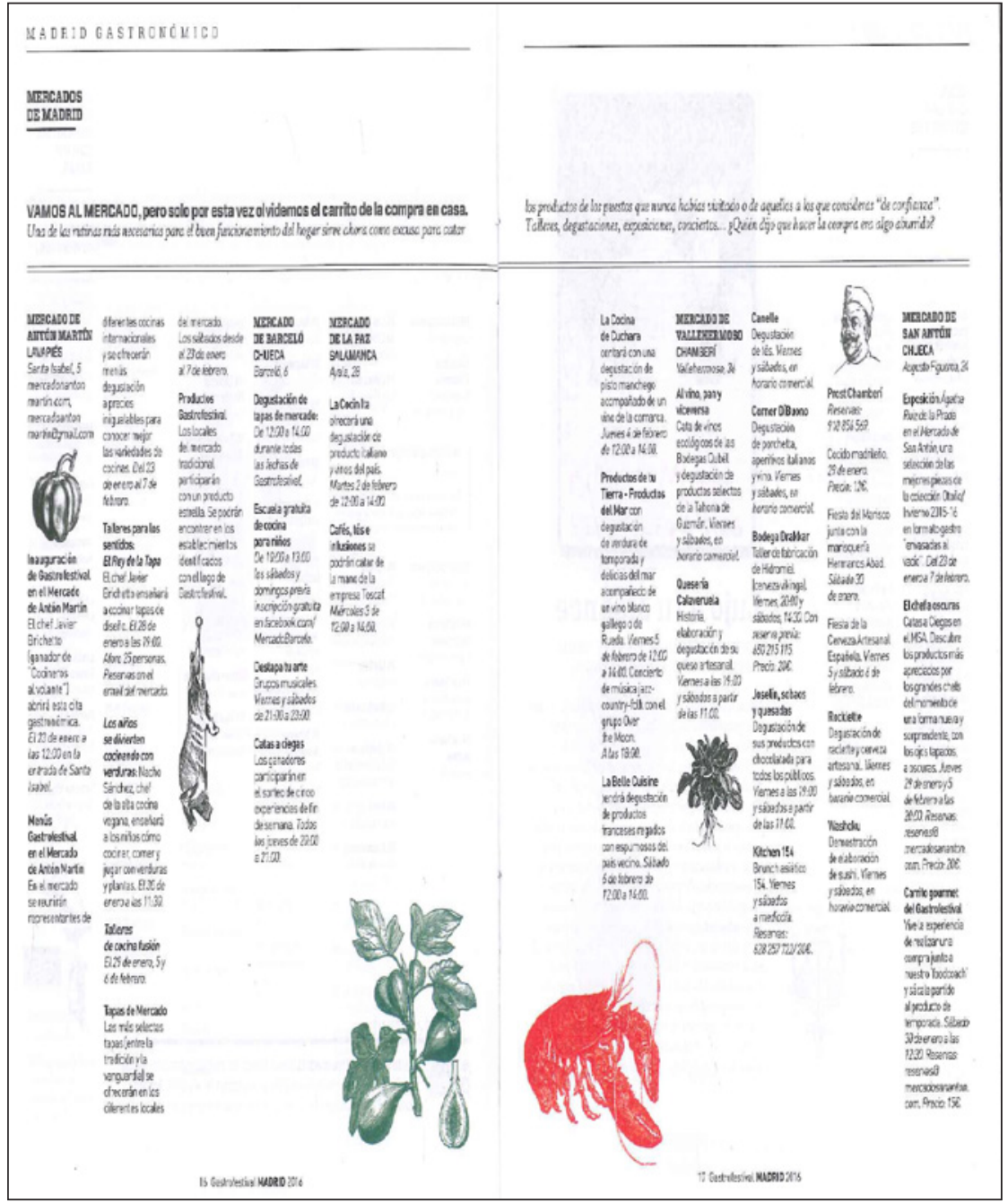

Fuente: Folleto Gastrofestival 2016. 
Los nuevos canales de comunicación generados por la categoría de Web 2.0 y 3.0 han ampliado el sentido de las comunicaciones y se ha pasado de un mensaje unidireccional a uno bidireccional con fuerte participación del usuario final en su generación y publicación (García, 2011).

Según el informe Food Tourism 2014, como se muestra en la Figura 8 los medios de comunicación empleados por los viajeros que buscan experiencias gastronómicas son, esencialmente, las relaciones personales e internet y las redes sociales.

\section{Figura 8 \\ MEDIOS DE INFORMACIÓN UTILIZADOS POR LOS VIAJEROS QUE DEMANDAN EXPERIENCIAS GASTRONÓMICAS}

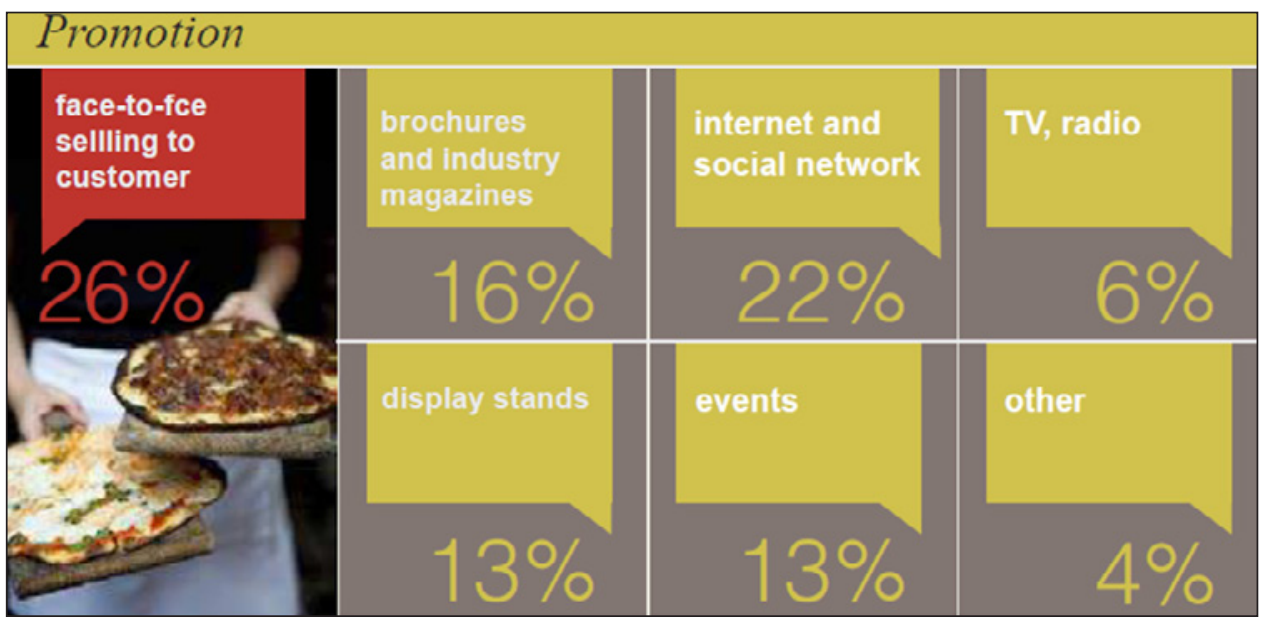

Fuente: http://www.blueroom.es/noticia/ya-esta-disponible-food-tourism-2014-nuevo-estudio-de-blueroom-project/

Internet permite al viajero sociabilizar la experiencia durante el viaje e incluso en la etapa de preparación. Esta socialización de la experiencia del viaje, implica una oportunidad para posicionar a la empresa cuando esta haya satisfecho o superado las expectativas de sus clientes, pero al mismo tiempo puede resultar negativa en el caso contrario debido a que el proceso de compartir experiencias entre usuarios se realiza sin participación ni control por parte de las empresas involucradas (García, 2011).

Mediante el uso de descripciones en texto, imágenes, mapas, videos y comentarios de usuarios e influencers es posible sentir o adelantar la experiencia del viaje (Serra 2011), algo de suma importancia para los destinos y productos que centran su oferta en el turismo experiencial, como es el caso de los mercados de abastos.

Un influencer es una persona que cuenta con cierta credibilidad sobre un tema concreto $y$, por su presencia e influencia en redes sociales, puede llegar a convertirse en un prescriptor interesante para una marca. En el caso de los mercados de abastos, los bloggers de tendencias, de gastronomía y los blogs de revistas de prestigio en el sector pueden 
ser claves como prescriptores del producto (las figuras 9, 10 y 11 recogen ejemplos de blogs y artículos en revistas de referencia en el sector turístico y de ocio que suponen una excelente estrategia de comunicación para los mercados de abastos).

Como se constata en la Tabla 5, que recoge información sobre webs y uso de redes sociales y blog propios, los mercados turísticos de Madrid presentan, a través de la red, su surtido de productos, actividades y servicios a los consumidores potenciales.

\section{Tabla 5}

INFORMACIÓN SOBRE WEB, BLOGS

PROPIOS Y FACEBOOK COMO INSTRUMENTO

DE COMUNICACIÓN DE LOS MERCADOS DE ABASTOS

\begin{tabular}{|c|c|c|c|}
\hline MERCADO & WEB & $\begin{array}{l}\text { BLOG } \\
\text { PROPIO }\end{array}$ & FACEBOOK /SEGUIDORES \\
\hline San Miguel & www.mercadodesanmiguel.es & & $\begin{array}{l}\text { Número de seguidores: } 37.621 \\
\text { www.facebook.com/MercadoDeSanMiguel }\end{array}$ \\
\hline San Antón & www.mercadosananton.com & & $\begin{array}{l}\text { Número de seguidores: } 26.210 \\
\text { www.facebook.com/mercadosananton }\end{array}$ \\
\hline Antón Martín & www.mercadoantonmartin.com & & $\begin{array}{l}\text { Número de seguidores: } 4.172 \\
\text { www.facebook.com/mercantonmartin/ }\end{array}$ \\
\hline San Fernando & www.mercadodesanfernando.es/ & & $\begin{array}{l}\text { Número de seguidores: } 6.988 \\
\text { www.facebook.com/mercadosanfernando }\end{array}$ \\
\hline Barceló & www.mercadobarcelo.es/ & & $\begin{array}{l}\text { Número de seguidores: } 2.129 \\
\text { www.facebook.com/MercadoBarcelo }\end{array}$ \\
\hline La Cebada & www.mercadodelacebada.com/ & & $\begin{array}{l}\text { Número de seguidores: } 1972 \\
\text { www.facebook.com/CentroComercialMercadodelaCebada/ }\end{array}$ \\
\hline Vallehermoso & NO WEB & & $\begin{array}{l}\text { Número de seguidores: } 1.650 \\
\text { https://www.facebook.com/Mercado-de-Vallehermoso/ }\end{array}$ \\
\hline $\mathrm{LaPaz}$ & http://www.mercadolapaz.es/ & & $\begin{array}{l}\text { Número de seguidores: } 1589 \\
\text { https://www.facebook.com/mercadodelapaz/ }\end{array}$ \\
\hline $\begin{array}{l}\text { Huerto de } \\
\text { Lucas }\end{array}$ & www.elhuertodelucas.com/ & & $\begin{array}{l}\text { Número de seguidores: } 8.224 \\
\text { www.facebook.com/pages/Huerto-de-Lucas }\end{array}$ \\
\hline Platea & http://plateamadrid.com/ & & $\begin{array}{l}\text { Número de seguidores: } 19.779 \\
\text { https://www.facebook.com/plateamad }\end{array}$ \\
\hline San Ildefonso & www.mercadodesanildefonso.com & $V$ & $\begin{array}{l}\text { Número de seguidores: } 11.572 \\
\text { www.facebook.com/MercadoSanIldefonso }\end{array}$ \\
\hline
\end{tabular}

Fuente: elaboración propia (25 Febrero 2016). 
Figura 9

ARTÍCULOS DE PRENSA OFRECIENDO NOTICIAS SOBRE LOS MERCADOS DE MADRID

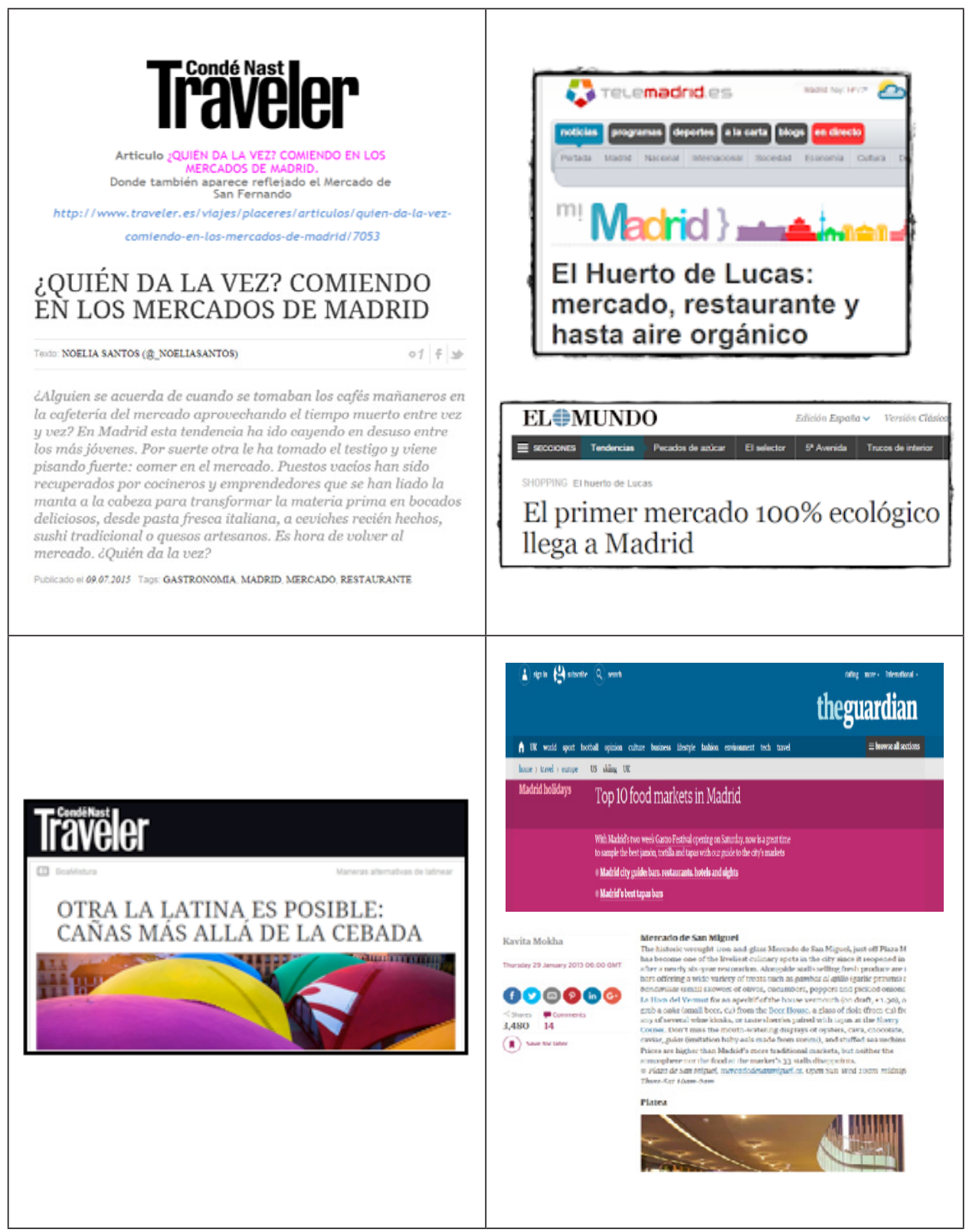

Fuente: www.traveler.es/; www.theguardian.com; www.elmundo.es; www.telemadrid.es 
Figura 10

COMUNICACIÓN POR MEDIO DE POST EN BLOGS DE REFERENCIA A NIVEL GASTRONÓMICO Y DE OCIO

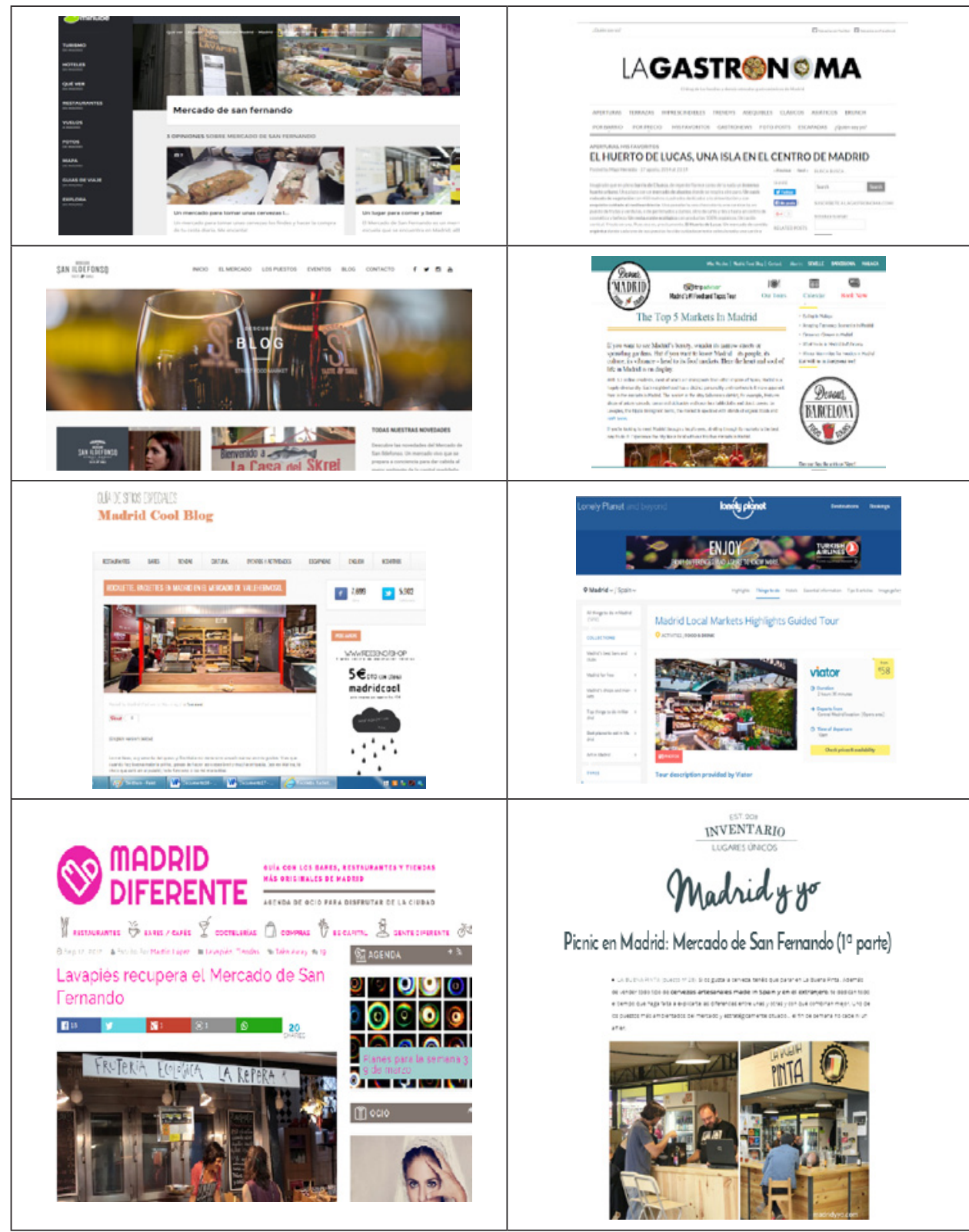

Fuente: www.minube.com; www.lagastronoma.com; www.mercadodesanildefonso.com; www.madridfoodtour com; www.madridcoolblog.com; www. lonelyplanet.com; www.madriddiferente.com; www.madridyyo.com 
Figura 11

ANUNCIO EN LA GUÍA DEL OCIO DE MADRID

DEL BLOG MADRID CONFIDENCIAL SOBRE ACTIVIDADES

GASTRONÓMICAS EN EL MERCADO DE LA CEBADA

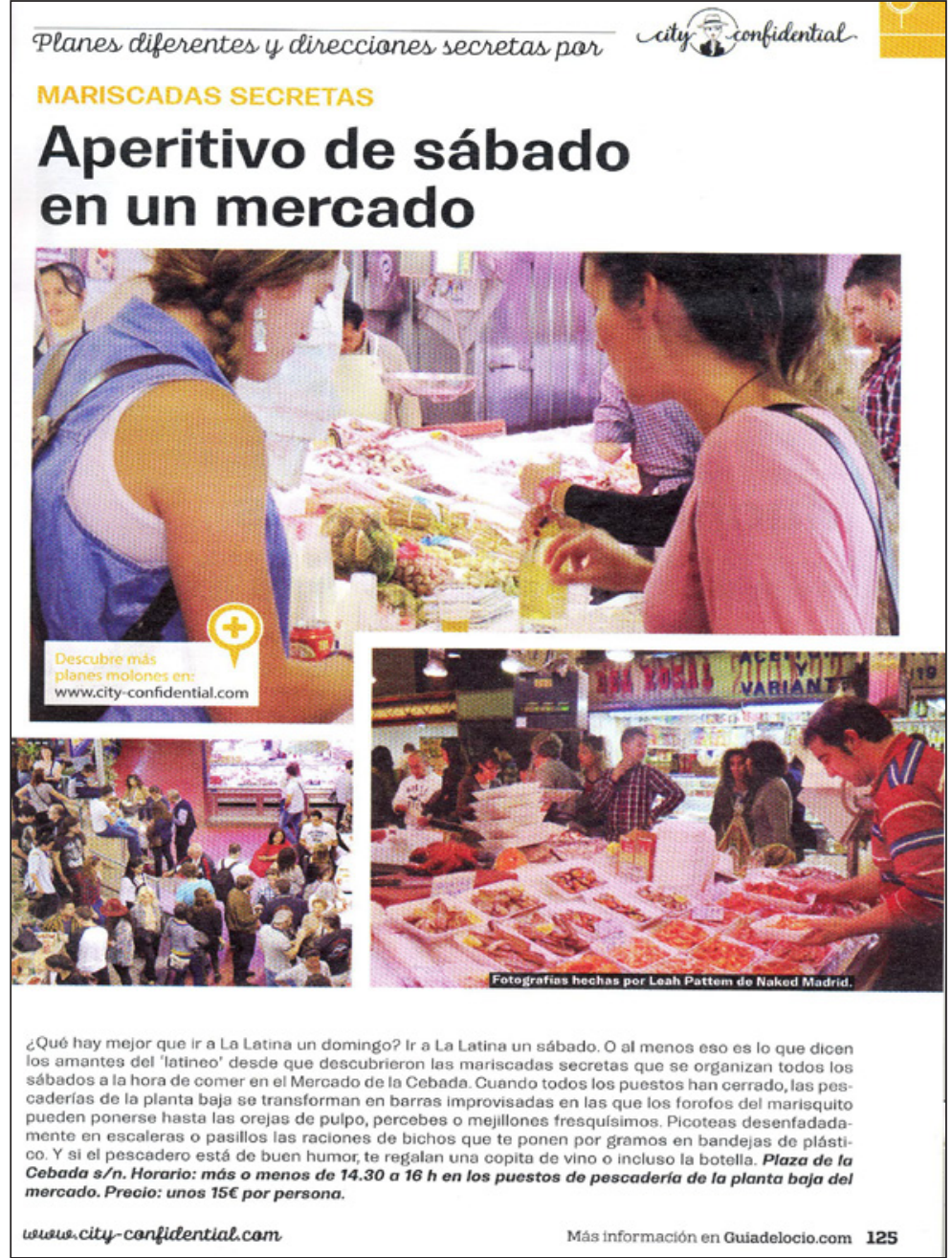

Fuente: Guía del ocio (Febrero 2016)

\section{CONCLUSIONES E IMPLICACIONES DEL ESTUDIO}

En un mundo estandarizado y globalizado, el turista amante de nuevas experiencias busca algo insólito, diferente y exclusivo, que únicamente se encuentre en aquel destino concreto que se visita de forma expresa. Los monumentos, los museos, la idiosincrasia 
de la gente, los mercados de abastos son exponentes de lo que esos nuevos consumidores buscan, puesto que ofrecen experiencias auténticas, propias de la sociedad local que se visita. En este sentido, los mercados de abastos son uno de los recursos turísticos promocionados donde lo local y lo turístico se dan la mano.

De acuerdo con la aproximación conceptual y la revisión de la literatura realizada en este artículo, es posible concluir que la gastronomía adquiere relevancia en el mercado turístico español como un elemento de diferenciación de España como destino turístico de experiencias. A su vez, el mercado cada vez más exigente y en busca de experiencias supone un nicho de mercado al que dirigir esas experiencias gastronómicas. Los mercados suponen aquí uno de los recursos turísticos a explotar como oferentes de "experiencias".

Los actuales viajeros, consideran las experiencias culinarias como un elemento clave a la hora de elegir el destino. Esa búsqueda de lo local lleva a los turistas a visitar los mercados de abastos, donde se puede percibir la idiosincrasia de la gente local, su forma de expresarse, de vender, de comprar, sus hábitos alimenticios, el estilo de vida de disfrute del ocio, los gustos y costumbres gastronómicas, etc.

Los datos de crecimiento de la oferta de ocio y restauración confirman que los mercados han sufrido una transformación convirtiéndose en centros del turismo de experiencia, gracias a su dinamismo y a las mejoras de gestión e inversiones para transformar su actividad tradicional.

Este trabajo ha permitido una clasificación de los mercados de abastos de Madrid que están realizando actividades en torno a las experiencias turísticas dirigidas al mercado local, nacional e internacional.

Esta clasificación también ha servido para demostrar que dichas acciones tienen una respuesta del mercado, dado los seguidores en redes sociales, el interés por la promoción de los mismos por los organismos turísticos locales y nacionales y la cantidad de información aparecida en medios de comunicación tradicionales, pero, ante todo, en redes sociales y blogs especializados en gastronomía, estilo de vida y tendencias.

Finalmente, un siguiente paso y, por tanto, una línea de investigación futura, sería estudiar en profundidad el uso de instrumentos de comunicación, ya que en la actualidad el producto se sitúa en sus primeras fases de ciclo de vida y la mayor parte de la inversión se ha realizado en diseñar el recurso turístico.

\section{BIBLIOGRAFÍA}

BALLART, J. y JUAN-TRESSERAS, (2001): Gestión del Patrimonio Cultural, Barcelona, Ariel.

BARRADO TIMÓN, D. (2004): «El concepto de destino turístico. Una aproximación geográfico-territorial», Estudios Turísticos, nº 160, pp. 45-68.

CRESPI VALLBONA, M. y DOMÍNGUEZ PÉREZ, M. (2013): «Urban strategies in tourist places. Cases of Madrid and Barcelona», Rotur, Revista de Ocio y Turismo, $\mathrm{n}^{\circ}$ 6, pp. 13-33.

CUENCA, M. y PRAT, A. (2012): «Ocio experiencial: antecedentes y características» Arbor. Ciencia, Pensamiento y Cultura, vol. 188, $\mathrm{n}^{\circ}$ 756, 265-281. 
GARCÍA HENCHE, B. (2011): Marketing del turismo rural, Editorial ESIC-Pirámide, Madrid.

HARRISON, R., (Ed.) (1994): Manuel of Heritage Management, Oxford, Butterworth \& Heinemann.

HERNÁNDEZ HERNÁNDEZ, F. (2002): El Patrimonio Cultural: la memoria recuperada. Madrid, Ed. Trea.

PINE, B. y GILMOUR, J (1998): «Welcome to the Experience Economy», Harvard Business Review , Vol. 76 (4), pp. 97-105.

QUAGLIERI DOMÍNGUEZ, A. y RUSSO AP. (2010): «Paisajes Urbanos En La Época Post-Turística. Propuesta De Un Marco Analítico», Revista Electrónica De Geografía Y Ciencias Sociales .Vol. XIV, núm. 323.

RICHARDS (2004): «¿Nuevos caminos para el turismo cultural? », Interacció. Barcelona, Centro de Estudios Culturales CERC, p. 1-15. Disponible en www.diba.es/cerc/arxinterac04/arcem1/richards/dipbarcelona

RIVERA MATEOS, M. (2013): «El Turismo Experiencial Como Forma De Turismo Responsable E Intercultural», en Jornadas sobre Investigación e Innovación para la Interculturalidad, Córdoba, pp. 199-217.

SERRA CANTALLOPS, A. (2011): Marketing Turístico, Editorial ESIC-Pirámide, Madrid.

TROITIÑO VINUESA, M.A., (1991): «Centro histórico, intervención urbanística y análisis urbano», Anales de Geografía de la Universidad Complutense, $\mathrm{n}^{\circ}$ 11, pp. 25-48.

TROITIÑO VINUESA, M.A. (1996): Turismo y desarrollo sostenible en ciudades históricas, Instituto de Turismo de España, Madrid.

VELASCO GONZÁLEZ, M. (2009): «Gestión Turística Del Patrimonio Cultural: Enfoques Para Un Desarrollo Sostenible Del Turismo Cultural» Cuadernos de Turismo, ${ }^{\circ} 23$, pp. 237-253.

VOGELER RUIZ, C. y HERNÁNDEZ ARMAND, E. (2002): El Mercado Turístico: estructura, operaciones y procesos de producción, Editorial Centro de Estudios Ramón Areces, Madrid.

WANG, R.F. y SIMONS, D.J. (1999): «Active and passive scene recognition across views», Cognition, vol. 70, pp. 191-210.

\section{WEBGRAFÍA}

BITACORADELAHENCHE (2015): Blog de viajes. [En línea] Disponible en: http:// bitacoradelahenche.blogspot.com.es

THE BLUEROOM PROJECT - TBP CONSULTING (2015): Consultoría de Comunicación y Marketing. [En línea] Disponible en: http://www.blueroom.es/noticia/ya-estadisponible-food-tourism-2014-nuevo-estudio-de-blueroom-project/

COMUNICATUR (2016): Revista especializada en el sector turístico. [En línea] Disponible en: http://www.comunicatur.info/es/los-mercados-de-abastos-y-las-ciudades-turisticas/ EL HUERTO DE LUCAS (2016):[En línea] Disponible en: www.elhuertodelucas.com/ EL MUNDO (2015): Periódico en Español. [En línea] Disponible en: www.elmundo.es EL VIAJERO (2015): Suplemento especializado en viajes del periódico El País. [En línea] Disponible en: http://www.elpais.com/elviajero. 
GATROFESTIVAL (2016): Evento de actividades en torno a la gastronomía. [En línea] Disponible en: http://www.gastrofestivalmadrid.com

GUIA DEL OCIO (2016): Guía de actividades de ocio. [En línea] Disponible en: http:// Www.guiadelocio.com

HOSTELTUR (2015): Revista especializada en el sector turístico. [En línea] Disponible en: http://comunidad.hosteltur.com/post/2011-06-08-mercados-de-abastos-tursticos

IET (2015): Instituto de estudios turísticos. Habitur. Encuesta sobre hábitos turísticos 2011. [En línea] Disponible en: http://estadisticas.tourspain.es/es-ES/estadisticas/ otrasestadisticas/habitur/anuales/Informe\%20Habitur\%202011.pdf

LA GASTRÓNOMA (2016): Blog de viajes especializado en gastronomía. [En línea] Disponible en: www.lagastronoma.com

LONELY PLANET (2015): Editorial de viajes. [En línea] Disponible en: www. lonelyplanet.com

MADRID COOL BLOG (2015): Blog de tendencias y ocio en Madrid. [En línea] Disponible en: www.madridcoolblog.com

MADRID DIFERENTE (2015): [En línea] Disponible en: www.madriddiferente.com

MADRID FOOD TOUR (2015): Agencia de turismo gastronómico en Madrid. [En línea] Disponible en: www.madridfoodtour.com

MADRID FUSIÓN (2015): Cumbre Internacional De Gastronomía En Madrid. [En línea] Disponible en: http://www.madridfusion.net/; http://www.madridfusion.net/ contenidos/pdf/widgets/24ES.pdf

MADRID TURISMO (2015): Portal de turismo de Madrid. [En línea] Disponible en: http://www.esmadrid.com

MADRID Y YO (2015): [En línea] Disponible en: www.madridyyo.com

MERCADO DE SAN MIGUEL (2016): [En línea] Disponible en: www.mercadodesanmiguel.es

MERCADO DE SAN ANTÓN (2016): [En línea] Disponible en: www.mercadosananton.com

MERCADO DE ANTÓN MARTÍN (2016): [En línea] Disponible en: www. mercadoantonmartin.com

MERCADO DE SAN FERNANDO (2016): [En línea] Disponible en: www. mercadodesanfernando.es/

MERCADO DE BARCELO (2016): [En línea] Disponible en: www.mercadobarcelo.es/

MERCADO DE LA CEBADA (2016): [En línea] Disponible en: www.mercadodelacebada.com/

MERCADO DE SAN ILDEFONSO (2016): [En línea] Disponible en: www. mercadodesanildefonso.com/

MERCADO DE VALLEHERMOSO (2016): Asociación de comerciantes del Mercado de Vallehermoso; [En línea] Disponible en: https://www.facebook.com/Mercado-deVallehermoso/

MERCADO DE LA PAZ (2016): [En línea] Disponible en: www.mercadolapaz.es/

MI NUBE (2015): Portal de Internet dedicado al ocio. [En línea] Disponible en: www. minube.com

PLATEA MADRID (2016): [En línea] Disponible en: http://plateamadrid.com/

SABOREA ESPAÑA (2015): Primera plataforma nacional con vocación internacional para potenciar el turismo y la gastronomía. [En línea] Disponible en: http://www. tastingspain.es/ 
THE GUARDIAN (2015): Periódico inglés. [En línea] Disponible en: www.theguardian.com TELEMADRID (2015): Cadena de televisión de la Comunidad de Madrid; [En línea] Disponible en: www.telemadrid.es

TRAVELER (2016): Editorial de viajes. [En línea] Disponible en: www.traveler.es TRIPADVISOR (2016): Web de viajes, planificación, reservas y consejos. [En línea] Disponible en: https://www.tripadvisor.es/PressCenter-i5542-c1-Press_Releases.html TUESPAÑA (2015): Portal de Turismo de España. [En línea] Disponible en: http://www. spain.info 
